\title{
The COMPosite NATURE OF INTERLANGUAGE AS A DEVELOPING SYSTEM
}

\author{
Longxing Wei \\ weil@mail.montclair.edu \\ Montclair State University
}

\begin{abstract}
This paper explores the nature of interlanguage (IL) as a developing system with a focus on the abstract lexical structure underlying IL construction. The developing system of IL is assumed to be 'composite' in that in second language acquisition (SLA) several linguistic systems are in contact, each of which may contribute different amounts to the developing system. The lexical structure is assumed to be 'abstract' in that the mental lexicon contains abstract elements called 'lemmas', which contain information about individual lexemes, and lemmas in the bilingual mental lexicon are language-specific and are in contact in IL production. Based on the research findings, it concludes that language transfer in IL production should be understood as lemma transfer of the learner's first language (L1) lexical structure at three abstract levels: lexical-conceptual structure, predicate-argument structure, and morphological realization patterns, and IL construction is driven by an incompletely acquired abstract lexical structure of a target language (TL) item.
\end{abstract}

Key words: interlanguage, composite, abstract lexical structure, lemmas, bilingual mental lexicon, transfer

\section{Introduction}

In most previous IL studies, L1 transfer is regarded as one of several processes responsible for IL, and language transfer is related directly to the developing IL system. One weakness of this is that the notion of language transfer, though it is often also called language interference or influence and is defined as a process in IL, usually implies its negative role in IL development, and the relationship between the learner's L1 and the TL is largely ignored. Recent refinements of language transfer theory have paid close attention to cross-linguistic influence in second language learning and regarded studies of cross-linguistic influence as an unavoidable and important part of SLA research. Researchers adopting universal approaches have found reconciliatory solutions between the traditional behaviorist and cognitive approaches (e.g., Kellerman and Sharwood Smith 1986; Færch and Kasper 1987; Ringbom 1987; Odlin 1989; Dechert and Raupach 1989; Gass and Selinker 1983, 1992; Gass 1996; inter alia). For example, Gass and Selinker (1992) hold that it is not incompatible to regard SLA as being affected by two interrelated processes: learners' utilization of their L1 knowledge and other languages known to them (the view advocated by Lado (1957)), and learners' build-up of a body of 
knowledge in which they test hypotheses formed on the basis of the available second language (L2) data (the view advocated by Dulay, Burt and Krashen (1982)). However, it becomes necessary to raise the questions: If the learner builds up and revises the interim system by gradually increasing the complexity of the TL system, what is the origin of IL? From the beginning, is the TL always the 'target' in projecting the sentential frame? If the TL is not sufficiently known to the learner to project the frame, is there no frame at all? Is there evidence that there necessarily always is a frame, and that the learner first falls back on an L1 frame and then in some incremental sense, moves toward a TL frame? How does the change to the TL frame begin? Can this beginning be detected and what are the steps toward achieving the TL frame?

To explore such questions, at an abstract level this paper makes several assumptions about the nature of the developing system of IL: First, the early IL system is a composite developing system in that at different times different linguistic systems are in contact, such as the learner's L1, the developing IL and the TL, which may contribute different amounts to the developing system of IL. Second, the mental lexicon contains abstract entries, called 'lemmas', which contain pieces of information about particular lexemes, and the bilingual mental lexicon contains language-specific lemmas, which are in contact in IL production. Third, abstract lexical structure contains several discrete but interacting subsystems: lexical-conceptual structure, predicate-argument structure, and morphological realization patterns, and such an abstract lexical structure in IL may have different sources, such as those from the learner's L1 and/or TL. Fourth, abstract lexical structure is modular and can be split and recombined in novel, yet constrained ways in constructing the linguistic system underlying IL, and parts of the lexical structure from the learner's L1 lexical entries may influence the lexical structure of incompletely acquired TL lexical entries in the developing IL. Fifth, learners may depend on their L1 strategies in order to map surface form onto functions in the TL. Their increasing familiarity with appropriate TL morphosyntactic structures will lead to a gradual fading of initially useful but inappropriate word choice or non-standard or ill-formed sentences. In a later state, the TL becomes more dominant in learners' IL system.

For comparative purposes, typical IL performance instances presented in this paper were collected from early-stage adult Chinese and Japanese learners of English as a second language (Wei 1995, 1996a). The analysis of the data focuses on how L1 lexical structure at various abstract levels (i.e., lexical-conceptual structure, predicate-argument structure, and morphological realization patterns) may fill 'gaps' in the composite IL construction. The abstract lexical structure model presented in this paper offers several implications for understanding SLA processes and mechanisms in general and the nature of the developing system of IL in particular.

\section{Interlanguage as a composite developing system}

One of the major assumptions underlying this study is that IL performance and development are also governed by the similar general language contact principles which govern language contact performance data in general, such as pidgins, creoles, and intrasentential codeswitching. The IL performance data to be discussed in this paper provide evidence that there are several potential linguistic systems involved in IL, such 
as learners' L1, the TL, and the developing IL (see Figure). Thus, the current definition of IL goes beyond the traditional one which simply defines IL as the learner linguistic system which is systematic, predictable, and developmental. As assumed, in any language contact phenomenon, there must be a Matrix Language (ML) (Myers-Scotton 1993 [1997]) which provides the grammatical frame for utterances. However, unlike other language contact phenomena, the ML of IL is defined as a composite of the de facto ML and the intended ML (i.e., the TL) (see Figure). Like other language contact phenomena, the learner's L1 is identified as the Embedded Language (EL). However, this EL may influence the de facto ML and thus may partially contribute abstract lexical structure (i.e., lexical-conceptual structure, predicate-argument structure, and morphological realization patterns) to IL utterances. What becomes crucial to the concept of a composite ML and to the concept of contributing EL is that abstract lexical structure is complex and organized into subsystems. The composite nature of the ML is caused by different constraints on the roles of the linguistic systems involved in the IL developing system, the TL being a 'preferred' ML because it is always the learner's target language and the L1 being an 'unfavorable' but 'unavoidable' EL because it may play an interfering role in the process of IL development.

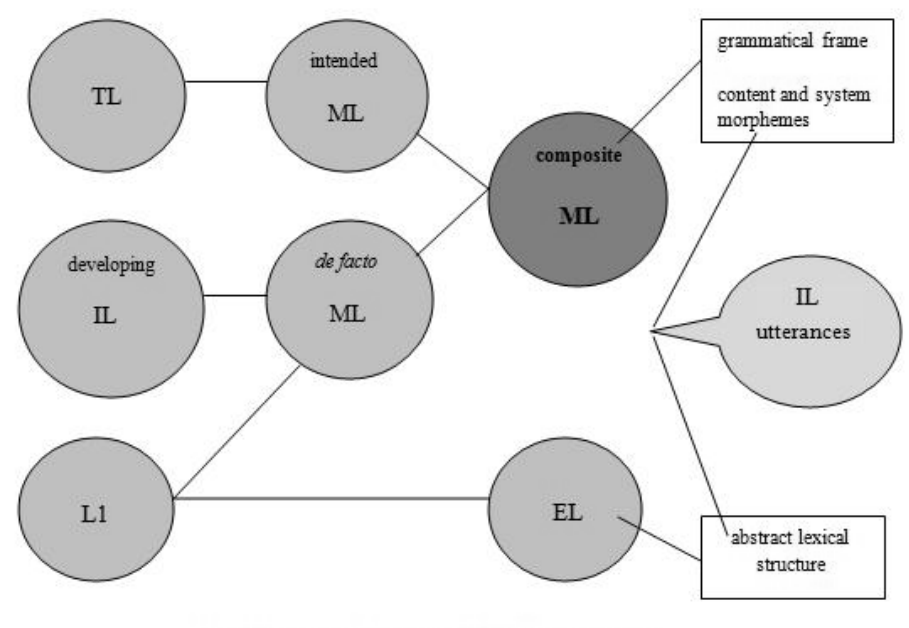

Interlanguage as a Composite Developing System

The present study defines IL as a composite developing linguistic system based on the following assumptions:

1. IL is always the learner language which shows the surface forms of the intended TL, but it also contains abstract lexical structures from both the L1 and the TL (MyersScotton 1994; Wei 1996b, 2000a, 2000b; Jake 1998). Such lexical structures are called 'abstract' in the sense that they cannot be clearly observed at any surface level of IL production but at a deep level of the mental lexicon. This 'deep' level is rather abstract because the mental lexicon does not simply contain lexemes and their meanings but more abstract elements called 'lemmas'. Lemmas are defined as abstract entries in the mental lexicon that support the surface realization of actual 
lexemes (cf. Levelt 1989; Myers-Scotton and Jake 1995; Wei 2001, 2002). This is because for each item, the mental lexicon contains its lemma information, that is, declarative knowledge about the word's meaning, and information about its syntax and morphology which is necessary for constructing the word's syntactic environment. For instance, the lemmas of know require a subject that expresses the thematic role of EXPERIENCER, an object that expresses the thematic role of PERCEPT (i.e., what is known), and these elements appear in a particular order; the lemmas of he require the word to be used of a male and that any following presenttense main verb must have the suffix $-s$ attached to it (i.e., inflectional morphology for tense marking). Lemmas also contain information about the word's phonological structure, syllabic composition, and accent structure. In addition, lemmas may contain information about the word's register, the kind of discourse it typically enters into, and its pragmatic function. Thus, the mental lexicon is defined as the speaker's internal representation of knowledge about the surface forms, that is, lemmas. It is assumed that lemmas are language-specific in the bilingual mental lexicon, and language-specific lemmas are in contact in IL production (Jake 1998; Wei 2001, 2002).

2. IL is a developing linguistic system, and, like other linguistic systems, its abstract lexical structure contains several discrete but interacting subsystems: lexicalconceptual structure, which conflates universally available semantic and pragmatic information; predicate-argument structure, which specifies the properties of verbs in different subcategories and how the expressed arguments are encoded grammatically; morphological realization patterns, which spell out surface devices for word order, case, agreement, tense/aspect marking, and so on (De Bot and Schreuder 1993; Myers-Scotton 1994, 2002; Jake 1994; Myers-Scotton and Jake 1995, 1999; Wei 1996a, 2001, 2002). Such an abstract lexical structure in IL may have different sources (Wei 1996b, 2000a, 2000b).

3. Abstract lexical structure is modular and can be split and recombined in novel, yet constrained ways in constructing the linguistic system underlying IL (Jake 1998). Parts of the abstract lexical structure from the learner's L1 lexical entries may influence the abstract lexical structure of incompletely acquired TL lexical entries in the developing IL, that is, each of the three levels of the lexical structure of IL may contain elements from the learner's L1 and/or the TL, resulting in a composite developing linguistic system.

Thus, due to the composite nature of IL, the complete acquisition of the TL lexical structure becomes crucial in IL development. Jake proposes two principles which are assumed to structure IL:

The target-language principle: To the extent possible, construct the IL from the TL lexical structure (1998: 341).

The complete-projection principle: To the extent possible, satisfy the requirements of the grammar of the matrix language through the specification of all requisite grammatical features of the entries in the mental lexicon (i.e. lemmas) (1998: 342).

The target-language principle can be said to be an IL principle that underlies the continual development of IL grammatical systems. From the beginning of learning, 
learners attempt to construct the developing IL from TL lexical structure. Along the IL continuum, as learners have more and more access to the TL, their IL structures become more targetlike. This principle predicts that "all IL surface structures are projected by TL-based lexical items in the grammatical system underlying IL" (Jake 1998: 342). This predication captures the generalization that TL lexical structure, real or putative, underlying all IL lexical items can be identified. Within the framework of IL as a composite linguistic system (i.e., a composite ML), L1 transfer or influence is limited to the extent of L1 congruence with the TL abstract lexical structure. In other words, it must be sufficiently targetlike so as to contribute to the abstract lexical structure of the composite ML. Thus, it is possible to argue that all L1 influence is TL-based (Jake 1998; Kellerman 1986; Giacobbe 1992).

The complete-projection principle is formulated based on the requirement that abstract entries in the mental lexicon (i.e., lemmas) must be as completely specified as possible (Levelt 1989). It is this principle that "drives the development of a grammatical system underlying the composite matrix language of IL" (Jake 1998: 342). Because the developing grammatical system underlying IL is recognized as a natural linguistic system, like any other linguistic system, it must satisfy to the extent possible the requirements of the projection principle (Chomsky 1981(b)), that is, the completeprojection principle requires lexically specified grammatical features referred to by modules of the grammar (i.e., all levels of abstract lexical structure) to be filled out in order to project phrase structures. This principle governs IL development in the sense that along the IL continuum, in different stages of learning learners may not have complete access or only partial access to the grammatical system whose phrase structures are projected by the TL entries in the mental lexicon (cf. Levelt 1989; Wei 2002). The implication of the complete-projection principle for understanding the ML of IL as a composite system is that when the TL entries in the mental lexicon are insufficiently developed or incompletely specified, the grammatical requirements for immediate speech production can be met with certain features of the abstract lexical structure from lexical entries from a linguistic system (e.g., the learner's L1) other than that of the TL. As assumed, if such an incomplete projection of TL abstract entries in the mental lexicon happens, L1 transfer or influence will occur in IL production. However, such a language transfer or influence is "subject to the same constraints as those on language contact in general and SLA in particular" (Jake 1998: 343). It is assumed that while universal requirements of language do exist, entries in the mental lexicon of a particular language are language-specific and they must be learned as such. The complete projection of the TL grammatical requirements "through the specification of all requisite grammatical features of the entries in the mental lexicon (i.e. lemmas)" (Jake 1998: 342) may never be achieved by second language learners. Consequently, a composite structure containing linguistic features of both the learner's L1 and the TL may result. Thus, the resulting IL structures may reflect incomplete acquisition of certain TL structures, creating gaps between the composite IL system and the TL system. 


\section{Sources of abstract lexical structure in IL}

In the preceding section, three assumptions are made about the composite nature of the developing system of IL. They are briefly repeated here to identify the nature of abstract lexical structure in relation to IL development.

1. Lemmas are language-specific in the bilingual mental lexicon, and language-specific lemmas are in contact in IL production.

2. Abstract lexical structure contains several discrete but interacting subsystems: lexical-conceptual structure, predicate-argument structure, and morphological realization patterns. Such an abstract lexical structure in IL many have different sources

3. Lexical structure is modular and can be split and recombined in novel, yet constrained ways in constructing the linguistic system underlying IL. Parts of the lexical structure from the learner's L1 lexical entries may influence the lexical structure of incompletely acquired TL lexical entries in the developing IL.

As assumed, the mental lexicon contains abstract entries (i.e., lemmas) which are pieces of information about particular lexemes, and the bilingual mental lexicon contains language-specific lemmas in contact. Such an abstract lexical structure becomes complex in IL because it may have different sources, such as those from the learner's L1 and/or the TL. The important assumption is that in SLA, parts of the lexical structure of L1 lexical entries may influence that of the incompletely acquired TL lexical entries. This section discusses the nature of IL complex lexical structure and its implications for IL construction.

As introduced above, lexemes have more abstract elements than surface lexical items themselves and such abstract elements are contained in complex lexical structure that lexemes have (cf. Talmy 1985; Rappaport and Levin 1988; Pinker 1989a, 1989b; Levelt 1989; Jackendoff 1990; Bock and Levelt 1994; Myers-Scotton and Jake 1995; Jake 1998; Wei 2001, 2002). Lexical structure is complex because it contains several levels, such as lexical-conceptual structure, predicate-argument structure, and morphological realization patterns. It has also been recognized that lexical-conceptual structure maps onto predicate-argument structure. This is because the theta criterion, for example, requires the mapping of lexical-conceptual structure (i.e., thematic structure) onto predicate-argument structure (i.e., syntactic structure). In addition to the thematic structure, the lexical-conceptual structure of a particular lexeme contains its semantic and pragmatic features and pointers to other lexemes with which it occurs (Levelt 1989; Bock and Levelt 1994; Myers-Scotton and Jake 1995; Jake 1998; Wei 2002). MyersScotton and Jake (1995) and Jake (1998) propose that morphological realization patterns be included in a formal consideration of lexical structure (cf. 'lexicalization patterns' discussed in Talmy (1985)). It seems necessary to identify morphological realization patterns as one of the levels of lexical structure because the predicate-argument structure of a particular lexical entry specifies that a thematic role is assigned or received, and the morphological realization patterns encode the realization of particular morpheme/ word order. In other words, it is the lexical head of a particular lexical entry that projects particular morphological realization patterns. For example, in English, the morphological realization patterns encode the realization of the THEME as an object of a verb (e.g., borrow the book), a verb-satellite (e.g., pick up the key/pick the key up), a verb + 
preposition (e.g., listen to the music), or a noun (e.g., student of linguistics/linguistics student). This means that the predicate-argument structure (i.e., thematic role assignment) is realized in particular morphological realization patterns (cf. the production model of Levelt (1989) and Bock and Levelt (1994), the bilingual production model of Myers-Scotton and Jake (1995), and the bilingual lemma activation model of Wei (2002)).

Such a formal consideration of abstract and complex lexical structure offers several implications for IL construction:

1. In a language-contact setting, the languages involved play unequal roles in structuring any constituents containing elements from both languages. Unlike other language-contact phenomena where there is always a clearly identified ML and the grammatical frame projected by the ML is always complete, in IL production, the ML of IL is a composite in that learners may not have complete access to the intended ML, that is, their knowledge of the TL, which is the intended language that frames constituents, is incomplete. Consequently, the ML of IL may contain elements at several abstract levels of lexical structure from the learner's L1 and the TL.

2. Abstract lexical structures from more than one linguistic system are in 'contact' in SLA. As in other language-contact situations, IL construction is necessarily projected by the lexical structure of the ML; however, the ML of IL is incomplete in the sense that it lacks certain aspects of the lexical structure of the TL items. Consequently, learners may use their L1 lexical structure and/or their partially acquired TL lexical structure in place of the ML lexical structure in order to frame IL constituents.

3. L1 transfer in IL construction is understood in terms of transfer of lexical structure at abstract levels from L1 morphemes. Such a transfer becomes necessary to fill particular 'gaps' in the incompletely acquired TL lexical item. However, the contributions (i.e., transfer) of L1 lexical structure at abstract levels are more constrained than those of the TL to the developing composite ML.

\section{Abstract lexical structure in the developing system of IL}

As assumed, abstract lexical structure has several implications for IL construction because L1 lexical structure may fill 'gaps' at the various abstract levels in the composite ML of IL. In this section, abstract lexical structure and its consequences in IL construction are described and explained at each of the three levels: lexical-conceptual structure, predicate-argument structure, and morphological realization patterns.

\subsection{L1 lexical-conceptual structure in IL construction}

As generally recognized, although the conceptual structure is not language-specific (cf. Levelt 1989; Bierwisch and Schreuder 1992), languages differ in the way they lexicalize the components of a given conceptual structure (Talmy 1985; Jackendoff 1991; Levin and Pinker 1991). As assumed in the present study, the lexical-conceptual structure of an IL lexeme may contain semantic/pragmatic features from an L1 counterpart. This is 
because although the L2 lexicon contains only those L2 lexical items that the learner has learned, some of these lexical items are not yet fully specified in terms of the semantic, syntactic, and morphological information that they contain. Thus, we call such an incompletely acquired lexicon IL lexicon. When learners' knowledge of the TL lexical items is partial or incomplete or when their TL lexical items are not sufficient enough to express their intended meanings, they may turn to similar or equivalent lexemes in their L1 at a certain point in IL production (Dewaele 1998; Wei 2003). If we assume that a preverbal message is not language-specific, then we are forced to assume that a different lexicalization pattern available to the speaker has to be enforced at a certain point in IL production (cf. Talmy 1985; Choi and Bowerman 1991). Consequently, languagespecific lemmas for particular lexical items in the bilingual mental lexicon are activated (Wei 2002), resulting in L1 transfer. L1 transfer in lexical-conceptual structure results in inappropriate lexical choices. Wei $(1994,1996 a, 1996 b)$ reports evidence that learners acquire simple TL content morphemes first which match up possible L1 conflation categories of semantic notions (i.e., several semantic notions are conflated in a single lexical item) (Talmy 1985; Pinker 1989a, 1989b; Jake 1994).

(1) She now do meal. She now busy. She yesterday look you.

(2) Open air condition.

(3) You close light.

(4) You come my house?

(5) You shut mouth.

(Chinese learners’ IL data; Wei 1995)

(6) There have English class, free. You go?

(Chinese learners' IL data; Wei 1996a: 423)

(7) You going filed trip?

(8) He is funny. His words in class laugh me.

(Japanese learners' IL data; Wei 1995)

(9) I study English for work in Japan. My parent want do me teacher ... teach English in Japan.

(10) Yesterday in library I look Japanese magazine.

(Japanese learners' IL data; Wei 1996a: 423)

These examples show that, among other things, the lexical-conceptual structures of the lexemes do not match those of the TL. In (1), do means 'cook', but in the L1 it also means 'play, work, write' in other cases. In (2), open means 'turn on', but it also means 'start' in the L1. In (3), close means 'turn off', but it also means 'stop, shut' in the L1. In (4), house also means 'apartment, building, home' in the L1, and the preposition 'to' is missing (since MOTION and GROUND are conflated in the verb in the L1). In (5), the TL satellite 'up' as part of the verb is missing since the verb shut itself expresses the same concept in the L1, and the same verb also means 'close, stop' in the L1. In (6), have means both 'possess' and 'exist' in the L1. In (7), the TL preposition 'on' is missing since the verb go itself is sufficient in the L1 to express the same concept, and 
the same verb does not require any preposition to indicate a specific direction or location in the L1. In (8), the semantic feature of 'cause' is incorrectly extended. The resulting causative lexical-conceptual structure affects the predicate-argument structure and its morphological realization patterns. In this example, the 'causee' is the PATIENT (me), which should be the AGENT (I) in the TL, and the IL 'causer' (his words) should be a PP STIMULUS (at his words) in the TL. Similarly, in the Japanese learners' IL, in (9), do means 'make', but it also means 'try, act, play' in the L1. In (10), look means 'read', but it also means 'see, look at, visit, observe' in the L1.

The above examples indicate that the subsystems, here the lexical-conceptual structure, of the TL lexical structure are not available to beginning learners. Such instances of L1 lexical-conceptual structure in IL production provide the evidence that in IL production, although learners use the TL lexical items, the selection of those items may be caused by their incomplete knowledge of the TL lexical-conceptual structure of particular lexemes. In other words, language-specific lemmas for the universal concepts based on learner's L1 may activate or retrieve the TL lexical items in an inappropriate manner, resulting in L1 transfer in lexical-conceptual structure. It is assumed that parts of lexical structure can be split and recombined (Jake 1998) in the developing IL. Along the IL continuum, as learners late acquire more and more knowledge of the TL lexical structure, their IL lexicon will expand to include the TL lexical-conceptual structure of particular lexemes and its lexicalization patterns.

\subsection{L1 predicate-argument structure in IL construction}

In addition to L1 transfer in lexical-conceptual structure, beginning learners may use TL content morphemes but frame them with their L1 predicate-argument structure. This means that IL verbs may project the number of arguments as required and the thematic roles assigned to each of the arguments as their counterparts in the L1, resulting in L1 predicate-argument structure in the composite ML. Because of their incomplete knowledge of certain TL lexical items, although learners may choose the right TL verbs, they may not know the predicate-argument structure as required by those verbs and use them inappropriately in IL production (Wei 1996a, 1996b). In other words, incomplete acquisition of TL lexical-conceptual structure maps onto incomplete TL predicateargument structure, one inducing the other. For example, in (1) above, the THEME of look is introduced without the preposition 'for' as required in the TL, since the counterpart verb 'zhao' ('look for') in the L1 does not need a preposition of any kind to introduce the THEME. In (8), the resulting causative lexical-conceptual structure affects the predicate-argument structure and the morphological realization patterns. Below are some typical examples of L1 predicate-argument structure in the composite ML.

(11) Today he help dinner.

(12) She cost me hundred dollar, ... bad tooth.

(13) Yes ... teacher report parent grade.

(Chinese learners' IL data; Wei 1996a: 422) 
(14) Please help me look my child.

(15) You're listening music?

(Chinese learners' IL data; Wei 1995)

(16) Wait. I first fill water in glass. Wait.

(17) He busy. He not help my homework.

(18) Parent provide money to me.

(Japanese learners' IL data; Wei 1996a: 422)

(19) I can wait you here.

(20) Why you ask many questions for me?

(Japanese learners' IL data; Wei 1995)

The above examples show that beginning or early stage learners attempt to use TL content morphemes; however, these content morphemes may occur in their L1 predicateargument structure. The examples in (11)-(15) reflect typical Chinese predicateargument structure used in IL production. In (11), help assigns the THEME directly to the object without the required preposition 'with' in the TL. In (12), cost takes the AGENT (the person who spends the money) as the subject, rather than the THEME (the thing on which the money is spent). In (13), report assigns the GOAL, rather than the THEME, to the object in the double-object dative construction. In (14), the preposition 'after' does not appear to introduce the THEME 'my child', since the Chinese counterpart verb 'zhaoliao' ('look after') does not need a preposition to introduce the THEME. This is shown again in (15), where the THEME of 'listen' is the internal object of the verb, rather than being introduced by the preposition 'to' as required in the TL, as it will be an argument of the Chinese counterpart verb 'ting'. Such a transfer of L1 predicate-argument structure also appears in Japanese learners' early IL. In (16), fill assigns the THEME to water, rather than assigning the PATIENT to glass and introducing the THEME by the preposition 'with' as required in the TL, and glass is assigned the LOCATIVE, rather than the PATIENT. In (17), the preposition 'with' as required in the TL does not appear to introduce the THEME, since in Japanese the verb help itself can assign the thematic role directly to the object. In (18), provide assigns the THEME, rather than the RECEIPIENT, to the object. In (19), the THEME 'you' is introduced directly by wait without the preposition 'for' as required in the TL, as it will be an internal object of the Japanese counterpart verb 'matsu' ('wait'). In (20), the GOAL ' $m e$ ' is introduced in a prepositional phrase, structurally subordinate to the internal object of the verb, 'many questions', the THEME. This structure reflects the Japanese counterpart verb 'suru' ('ask') which projects the GOAL as a postpositional object with the postposition 'ni', rather than the internal object indicated by the particle 'o'.

These examples show how L1 may contribute to the composite ML of IL at the level of predicate-argument structure. Those early IL predicate-argument structures are affected and projected by the L1 lexical-conceptual structures. While it is true that the L2 grammatical system is always second language learners' 'target', the ML of IL is in fact a composite of structures from multiple sources. These sources may include lexical- 
conceptual structures from the L1 or the intended TL, giving its content morphemes; predicate-argument structures from the L1, giving its morphosyntactic fames, and possibly universal strategies for frame building. Consequently, the composite ML of IL and the frame it projects do not necessarily match the TL and its frame (cf. MyersScotton 1994). It is in this sense that we assume that the production of L1 predicateargument structure, in addition to other levels of abstract lexical structure, which makes the ML of IL a composite.

\subsection{L1 morphological realization patterns in IL construction}

Recall that one of the levels of abstract lexical structure is morphological realization patterns, which are a positional level realization of higher levels of lexical structure (i.e., surface devices for word order, case, agreement, tense/aspect marking, etc.). In early stages of second language learning, L1 influence in this aspect of IL can be obvious. Wei $(1995,1996 a, 1996 b)$ reports many examples of L1 morphological realization patterns in IL production. Below are some typical ones.

(21) Because I don't know English, I English not speak.

(22) I like ... accounting people job because I study English, just more study English.

(23) My husband in USC study.

(Chinese learners’ IL data; Wei 1995)

(24) You too go? We have three ticket.

(25) Outside code, inside warm.

(26) (on the phone) Hello ... She not in home. She at outside at playground playing. You come? You not come? I tell her. Bye.

(27) Go swim? No. Parent no go, you no go swim.

(28) You not go library, I go.

(29) Tomorrow I no go work. I sick.

(Chinese learners' Il data; Wei 1996a: 421)

(30) In Japan student English junior high school start.

(31) I in Japan my city like.

(Japanese learners' IL data; Wei 1995)

(32) I from Japan arrive, now live in room ... apartment, I, friend and EPI teacher. EPI teacher help me English speak ... kind, nice teacher.

(33) Here everything expensive. I everyday use bike. Taxi? No. I live not far.

(34) I go to party with friend tomorrow. We together cook, interesting.

(35) Speak English difficult. I English ... speak not well.

(Japanese learners' IL data; Wei 1996a: 421)

Examples (21)-(29) show that, among other things, beginning Chinese learners of English use L2 content morphemes to express their intended meanings, but they tend to employ their L1 morpheme order (cf. Givón 1984; Talmy 1985). In Chinese, though the 
basic word order is SVO, any constituent can be moved to the sentence initial position or before the verb for topicalization or emphasis. In (21), the direct object 'English' appears before the verb. In (22) 'more' appears before the verb phrase 'study English'. In (23) the prepositional phrase of location appears between the subject and the verb. Based on the context, any constituent or element, such as the copula, AGENT, or THEME, can be left out, as in (25), (26) and (27). In Chinese morphological realization patterns, there are few auxiliary verbs and no system morphemes for 3rd person singular, plural, and tense/aspect marking. Thus, in Chinese morphological realization patterns, tense/aspect is expressed implicitly, as in (24), (26) and (27), or by other means, such as by time adverbials, as in (29); negation is realized by placing the negative particle immediately before the verb, as in (21), (26), (27), (28) and (29); interrogative is realized by rising intonation, as in (24), (26) and (27); and plural is realized by specific cardinal numbers, as in (24). The examples show that while beginning Chinese learners use TL content morphemes, their IL is structured by a composite ML in which the morphological realization patterns largely come from their L1 (Wei 1996b).

Similarly, beginning Japanese learners of English use TL content morphemes but follow their L1 morphological realization patterns. In Japanese, the basic word order is SOV, as in (30), (31), (32) and (35), and any constituent must be placed before the verb, as in (30), (31), (32) and (34); negation is realized by placing the negative element after the verb, as in (33) and (35). Also, in Japanese morphological realization patterns, there is lack of auxiliary verbs for tense/aspect marking, negation, etc. and other system morphemes as required in the TL, such as certain determiners as in (33) and (34), 3rd person singular as in (32), and plural as in (34). Consequently, like those Chinese learners, beginning Japanese learners tend to produce bare forms in which TL content morphemes are inserted into L1-based IL frames or frames not found in the TL (Wei 1996b).

One of the major assumptions underlying the composite ML model is that lemmas in the mental lexicon (in this case, the bilingual mental lexicon) are language-specific and contain all the information necessary to project actually occurring surface forms. L1 lexical structure at the level of morphological realization patterns may be employed by early stage second language learners to fill a 'gap' in the lexical structures projected by the incompletely acquired ML of the TL. Thus, language transfer or influence (in this case, L1 transfer or influence) at any level of abstract lexical structure in IL development is assumed to be language-specific lemma transfer or influence.

\section{Content vs. system morphemes in IL production}

The distinction between content and system morphemes depends on two lexical features: [ \pm thematic role assigner/receiver] and [ \pm quantification], and is theoretically independent of the lexical categorization feature of the morpheme. Nouns, descriptive adjectives, most verbs, and some prepositions are prototypical content morphemes. They can be characterized as categories that are potential thematic role assigners or receivers. Those morphemes that assign or receive thematic roles are content morphemes. In contrast to content morphemes, system morphemes do not assign or receive a thematic 
role of any kind. Prototypical system morphemes are quantifiers, specifiers and inflectional affixes.

In this paper, the content vs. system morpheme distinction is slightly recast in light of the sources of morphemes. Assumptions regarding the sources of morphemes refer to differences in the levels of abstract lexical structure. According to Myers-Scotton and Jake (1995) and Wei (2000a, 2002), at the conceptual level, speaker intentions are mapped onto semantic/prgamtic feature bundles. While speaker intentions are not initially language-specific, these bundles are language specific. This is the mapping of speaker intentions to lemma entries. It is assumed that abstract entries in the mental lexicon support the surface realization of actual lexemes. Lemmas contain all aspects of lexical information necessary to project a morphosyntactic frame. This is because they activate morphosyntactic procedures spelling out the lexical knowledge of the lexical entry. Such 'directly-elected' morphemes (cf. Bock and Levelt 1994; Wei 1996b; Jake 1998; Myers-Scotton 2002) supported by those activated lemmas in the mental lexicon are content morphemes.

According to Wei (1996a, 1996b, 2000a, 2000b), some morphemes are selected from a limited number of choices in the projection of the structure required by other lexical items. Such morphemes are 'indirectly-elected' along with 'directly-elected' elements. Indirectly-elected morphemes are required as part of the realization of the predicateargument structure and morphological realization patterns, but they do not represent lexical concepts independent of the directly-elected elements with which they are accessed. Indirectly-elected elements include prepositions like to in listen to the story and at in look at the picture, and particles like up in pick up the key and on in put on the coat. The treatment of indirect election followed here relates speaker intentions to lemma entries. For example, in certain semantic/pragmatic contexts, such as 'definiteness', 'specificity', etc., the lemma supporting a noun directly elected by a nominal argument projects the phrase structure with a determiner, such as a possessive, a demonstrative or an article. This means that the possessive, the demonstrative or the article is indirectly elected by the functional level projections of the lemma supporting the noun via activated semantic/pragmatic features. In other words, indirectly-elected lemmas only arise from projections of directly-elected lemmas. For example, my, the, and that in my brother read the book on that table are indirectly-elected elements with their respective nouns. This is because the lexical-conceptual structure of a particular lemma entry of a noun requires a determiner to serve certain semantic/pragmatic purposes.

Certain morphemes are the result of the spelling out of aspects of the morphological realization of a lexeme. They do not reflect the semantic/pragmatic features conflated in the lexical-conceptual structure but are only activated in the projection of morphophonological encoding at the positional level. For example, case assignment reflects predicate-argument structure and some phi-features license phonetic realizations, but they are not indirectly elected by semantic/pragmatic features as required by speaker intentions. Such morphemes are called 'structurally-assigned' morphemes (Wei 1996b).

Based on their different sources, the division of morphemes into those which are directly-elected and those which are not results in two types of morphemes: content morphemes and system morphemes. Directly-elected morphemes, those supported by lemma entries activated at the conceptual level, are content morphemes; morphemes 
whose lexical entries are 'called' to map lexical-conceptual structure onto predicateargument structure or predicate-argument structure onto morphophonological realization are system morphemes. Both indirectly-elected and structurally-assigned morphemes are system morphemes, but their sources are different. This difference lies in the fact that some system morphemes represent lexical-conceptual structure, but others do not ((see the 4-M model of Myers-Scotton and Jake 2000 for the classification of system morphemes).

The examples of IL production discussed above show that early stage or beginning second language learners can communicate with TL words which have constant semantic and pragmatic properties. The early categories acquired by learners are content morphemes, an observation compatible with what Radford calls "the lexical-thematic analysis of early child [L1] sentences" (1990: 47). Those learners use especially certain content morphemes for simple communicative purposes.

In language contact situations, system morphemes must come from the ML, not the EL, and are acquired differently (i.e., with different frequency of occurrence and accuracy) in SLA. For example, in intrasentential codeswitching, it is the ML which provides the morphosyntactic frame and required system morphemes, rather than the EL, and this is also true in other language contact phenomena, such as SLA. Therefore, if the TL is the target ML in IL, IL system morphemes ought to come from the TL. Why don't they? The answer, as assumed, is that the TL is not really the ML yet. Learners may use L1 morphosyntactic frame before they acquire TL system morphemes. However, they recognize that L1 system morphemes cannot be 'physically' realized (i.e., actually put into use) in intended TL production (they are trying to speak English anyway), so what they often do is produce 'bare forms': unmodified or uninflected TL content morphemes. Since the TL is the intended ML, but not the achieved ML, TL system morphemes may occur, but often incorrectly.

In addition to the distinction between content and system morphemes and subcategories of system morphemes, which cause differential frequency/accuracy acquisition orders, the composite ML model further assumes that because of their incomplete acquisition of the TL abstract lexical structure, learners acquire semantically transparent TL system morphemes before those under INFL and TL semantic categories which are congruent with those of L1 before those which are not.

\subsection{Unequal acquisition of system morphemes}

One of the major assumptions underlying the present study is that IL constructions are driven by different types of morphemes. It argues that the reason why morphemes are not acquired at the same rate is that they are projected differently from the mental lexicon. It claims that early IL forms are the consequences of learners' incomplete acquisition of the abstract lexical entries of the TL. Three types of morphemes are identified, depending on how they are activated from the mental lexicon (i.e. directlyelected, indirectly-elected, or structurally-assigned). The empirical IL data of L2 morpheme acquisition provide evidence that not all system morphemes are acquired equally (see Wei 1996b). This section explains the phenomenon in terms of degrees of semantic transparency of system morphemes. 
Learners acquire semantically transparent TL system morphemes before they acquire morphemes under INFL. Semantically transparent system morpheme include progressive '-ing', plural marking, and certain determiners, and system morphemes under INFL include tense/aspect marking, auxiliary verbs, and subject-verb agreement (cf. VanPatten 1984a, 1984b). Different from other classifications of morphemes based on categorydefining features, morphemes are classified in terms of how they are activated from the mental lexicon. It has been found that learners acquire system morphemes internal to a single maximal category (i.e., within a maximal category) at D-structure before those external to a maximal category (across maximal projections) at S-structure (cf. MyersScotton and Jake 1995).

(37) We tomorrow have a quiz. I tell teacher I'm not ready.

(38) You doing your homework?

(39) She read fast but not understand.

(40) You not take these two books.

(41) The table led break.

(42) I not have the car door key.

(Chinese learners' IL data; Wei 1996a: 426)

(43) I living with my Japanese friend.

(44) During the break ... next week ... I go see my uncle. He live in Atlanta.

(Japanese learners' IL data; Wei 1996a: 426)

These examples show that although learners begin to use certain 'internal' system morphemes, such as plural, determiner and progressive '-ing', they still have difficulty in using 'external' system morphemes, such as auxiliary verbs for tense/aspect marking (cf. Jake 1994). Some system morphemes (e.g., determiner) occur in 'slots' in a maximal category (e.g., NP) projected by a content morpheme. Learners acquire system morphemes that are part of a lexical category (e.g., plural is part of a noun, and '-ing' is part of the present participle lexeme). As predicted, these are acquired before those requiring morphosyntactic information across maximal projections (e.g., subject-verb agreement or tense/aspect in INFL).

Another possible reason for certain so-called 'internal' system morphemes (i.e., 'indirectly-elected') to be acquired earlier is that they are semantically more compatible with those similar or equivalent concepts in learners' L1, whether they are morphosyntactically realized by specific morphemes or not. Even though learners' knowledge of the TL abstract lexical structure is incomplete at a certain stage of learning, such system morphemes are relatively easier to acquire. In other words, learners have more access to semantically more transparent system morphemes than those which are less semantically transparent.

\subsection{Unequal acquisition of content morphemes}

In addition to the fact that content morphemes are acquired first before other types of morphemes, it has been observed that content morphemes are not always acquired at the 
same rate. Learners acquire TL semantic categories which are congruent with those of L1 before they acquire those which are not. For example, verb complexes like 'bring up' and 'look down upon' in English are not congruent with verb forms in Chinese or Japanese, so they are acquired later. Verb complexes contain a type of surface constituents termed 'satellites'. "Satellites are certain immediate constituents of a verb root other than inflections, auxiliaries, or nominal arguments" (Talmy 1985: 102-3). A verb root together with its satellite(s) forms a constituent in its own right: a verb complex. The '[ ]' in the following examples shows the missing satellite(s) as required in English.

(45) A: You're listening [to] music?

B: No. I'm looking [at] pictures.

(46) Please help me look [after] my child.

(47) Pick [up] the key for me. I dropped it.

(48) Sure. You can hear [from] me from that university.

(49) I can wait [for] you here.

(Chinese learners' IL data; Wei 1996a: 427)

(50) He pick me [up] every day.

(Japanese learners’ IL data; Wei 1996a: 427)

Morphemes like satellites are classified as indirectly-elected morphemes. They are predicted to be acquired earlier than structurally-assigned morphemes. However, this is only one of the possible explanations. Another possible explanation is that because learners' incomplete knowledge of certain TL content morphemes which contain satellites (i.e., verb complexes), they may encounter more learning difficulty in acquiring them than other content morphemes which do not contain satellites (i.e., single verbs). One of the possible reasons lies in the fact that learners may have only partial access to the TL content morphemes containing satellites which are incongruent with the equivalent lexical entries in their L1. The learning difficulty is caused by the incongruence between certain TL and L1 word structures. For example, the verb root in Chinese and Japanese stands alone as an entire word, whereas in English it may be followed by one or more satellites to "make up a polysynthetic verbal word" (Talmy 1985: 61). The above examples indicate that learners acquire single verbs which match their L1 word structures before they acquire verb complexes.

It has also been observed (Wei 1996a, 1996b) that learners acquire the semantic features which are conflated into 'semantic/pragmatic feature bundles' (Myers-Scotton and Jake 1995; Wei 2001a, 2001b, 2002) which are close or identical to those in the L1 earlier and vice versa. For example,

(51) My coat is in your car.

(52) My daughter is in house. She is always in home.

(53) You wear this jacket and go to the meeting.

(54) She want me paint her bike blue.

(Chinese learners' IL data; Wei, 1996a: 427) 
These examples show that 'in' and 'at' are conflated in the L1 as in (51) and (52), but not in the TL. In (53), MOTION + MANNER are not conflated in the L1, whereas they are in the TL. In (54), MOTION + CAUSE are conflated in the L1 as in the TL.

The observation of unequal acquisition of content morphemes provides further evidence that learners' incomplete knowledge or acquisition of TL abstract lexical structure, at the level of lexical-conceptual structure, predicate-argument structure and/or morphological realization patterns, causes the existence of the composite ML of IL. When we say that second language learning involves moving through stages to more closely approximate the TL, what we really mean is that learners move away from an IL for which the idea of an ML vs. an EL is relevant, to a monolingual IL, one in which both the morphemes and grammar come from the TL. The concept of the ML vs. EL opposition is only relevant in constituents with lexical structures or lexicalization patterns from two or more languages. In other words, the ML in learners' IL is shrinking when learners are moving closer to the TL. This is because learners' IL now consists of most TL lexical-conceptual structure, predicate-argument structure and morphological realization patterns.

\section{SLA as a language-contact phenomenon}

It has been assumed that SLA is a language-contact phenomenon, and thus principles which structure other language-contact phenomena should also structure IL. Several issues have received attention.

First, studies of pidginization and creolization continue to contribute valuable empirical observations and insights to the understanding of IL development in particular and SLA in general. For example, Andersen and Shirai (1996) include reference to the processes of pidginization and creolization in their investigation of SLA of verb morphology in relation to tense and aspect. They note that the notion of L1 transfer alone cannot explain learners' production of certain L2 morphemes for tense and aspect marking, such as overextension of '-ing'. They suggest that there may be an interaction between universal factors like markedness and prototype and L1 factors, and such an interaction may influence second language development. Such a type of interaction has also been observed in other aspects of SLA, such as phonology (Eckman 1977; Major 1987), morphology (Andersen 1983a, 1983b; Jake 1998; Wei 1996b, 2000a, 2000b), phonology and morphology (Hatch 1983), syntax (Zobl 1980a, 1980b; Gass 1984), and semantics (Tanaka 1983; Shirai 1989).

Second, grammatical competence under L1 attrition in bilinguals shows many of the same properties as grammatical competence at various stages of SLA. Seliger (1996) finds that bilinguals exhibit primary language attrition when they use mixed forms in situations that are not sociolinguistically appropriate and where the audience does not share or speak the L2. Primary language attrition surface performance may resemble forms of language mixing, such as that of which occurs in normal bilingualism but can be distinguished from it on the basis of when and how it is used in a social context (see Seliger 1996: 610-4 for discussion of differences between code-mixing and language attrition). Pfaff (1979), Seliger (1996), Kuhberg (1992), and Cook (2003) among others provide strong evidence that the attrition manifests itself in syntax, morphology, and 
calquing of language material from various levels from L2 into L1. Seliger considers two internal sources of data or evidence for the construction of a grammar of L1: "One source of change is the other grammar that exists in the mind of the bilingual, the grammar of the L2 and the other source is what remains of UG abilities" (1996: 617). Accordingly, as a result of primary language attrition, changes in the L1 grammar contain transfer from various linguistic elements in the L2, and those elements in the L2 that are more in agreement with core universals (i.e., those elements not belonging to the periphery (Chomsky, 1986)) will more easily transfer. Myers-Scotton (2002) offers a detailed and critical overview of attrition studies. She argues that "a language may be marked by extensive analogical leveling and substitutions, but there is always a clear morphosyntactic frame, even if a composite Matrix Language is its source" (2002: 185). Similarly, based on the findings from her study of adult speakers of American Russian with severe attrition, Polinsky observes that "the loss of grammatical system is nonrandom," and she states, "even significant language loss has a principled grammar of its own" (1997: 401).

Third, studies of bilingualism in the individual and society provide a context for research in all of language contact situations. Dorian (1981), among others, recognizes a proficiency continuum that may develop between two languages in contact, resembling in some respects a creole continuum. Individuals can be located at various points along such a continuum, depending on their current level of dominance or proficiency in one or the other of the languages, and they will show the effects of language contact to differing extents. Dorian (1981: 15) observes that in many cases changes occur in 'healthy' languages. Such changes can be described as simplifications in that they may result in the elimination of one or more competing structures, or reanalysis of structures, and thus make the language more regular and transparent. Similarly, Andersen (1982) proposes that speakers of a language undergoing attrition will tend to preserve and overuse syntactic constructions that reflect underlying semantic and syntactic relationships more transparently. Beniak, Mougen and Valois (1984/5) use the term 'convergence' to refer specifically to the gradual elimination of non-congruent forms in languages in contact. According to them, interference is the introduction of new forms or rules in one language under influence from another where they already exist and are in contact (e.g., the loss of the accusative postposition in the Kupwar variety of Kannada due to long-term contact with the other languages in use there, which do not possess accusative postpositions). Romaine (1989) offers a detailed study of some of the linguistic and social consequences of societal bilingualism. According to her, linguistic resources are organized in multilingual communities in different ways, and "where languages are in contact, linguistic phenomena such as borrowing, interference and transfer will generally be found" (1989: 77). Crucially, she notes that the balance between languages in contact is not stable but may change over time. Thus, a bilingual community may shift from the use of one language to another, including gradual linguistic changes, as a result of long-term contact. In other words, the codes used by speakers of different languages in contact may not be stable, and bilingual competence may span several unequally developed codes. Thus, a bilingual may be fluent in both languages taken together but may not have the same proficiency as a monolingual in either of the languages on its own. She emphasizes that the bilingual's system is not the 
same as the monolingual's in some respects, but there is no reason to believe that the bilingual system is a problematic mode of organization or a defective one.

Lastly, recent research in codeswitching (some researchers use the term code-mixing for intrasentential codeswitching and the term code-switching for intersentential codeswitching. Here we use codeswitchng as a general term to cover both cases.) has provided not only new empirical evidence for structural constraints on mixed or switched codes and inputs to current grammatical theory but also a site for the testing of claims about IL developmental constraints and acquisitional sequence. Directly relevant to IL research is the distinction between the ML (i.e., host or base language) and the EL (i.e., guest language) used by many researchers in describing a particular case of codeswitching. This distinction is only relevant to the intrasentential codeswitching phenomenon. Although there are a number of criteria that have been proposed to identify the ML in discourse involving codeswitching (e.g., Klavans (1985) and Treffers-Daller (1991): structural language of INFL in the Government and Binding model; Nishimura (1989): overall structural properties of the sentence such as Topic-Comment structure; Kamwangamalu and Lee (1991): frequency count of elements in the sentence; MyersScotton (1993): overall morphosyntactic frame of the sentence; Bhatia and Ritchie (1996): multifactorial approach drawing from the categories as identified), the existence of the ML and its role in the structural organization of codeswitching have been recognized. Codeswitching is seen as a language contact phenomenon because two (or more) languages are involved in the same discourse, whether intrasententially or intersententially. Like all linguistic behavior, codeswitching is governed by a set of internalized rules. Although there are different approaches to the structural analysis of codeswitching, one thing agreed upon by most researchers is that codeswitching is not simply a randomly 'mixed' system but is constrained in various identifiable and explainable ways. One of the crucial claims is that the ML and the EL do not play equal roles in codeswitching. The ML is more activated than the EL in structuring the grammar of the sentence containing codeswitched constituents and the occurrence of ML morphemes is freer and more frequent than that of the EL morphemes. This means that the ML provides all syntactically relevant system morphemes and most content morphemes, but the EL only provides some content morphemes for realizing certain semantic-pragmatic features.

One of the major assumptions presented in this paper is that SLA is a languagecontact phenomenon, and thus principles structuring other language-contact phenomena also structure IL, that is, the structural principles governing codeswitching are also at work in SLA and affect IL development. Classic codeswitching is defined as constituents containing morphemes from both the ML and the EL. However, IL is not the same as classic codeswitching in terms of a clear distinction between the ML and the EL. Thus, this study extends the definition of codeswitching to include IL systems with elements (i.e., lexical items, types of morphemes, and grammatical structures) from two or more languages. There are at least three linguistic systems in contact in SLA: the L1, the TL, and the developing IL (see Figure). Two linguistic systems are ML candidates: the TL is the learner's "intended ML," and the abstract grammatical system underlying the developing IL is the "de facto ML" (Jake 1998: 362). Because of learners' insufficient knowledge of the TL, the intended ML is incomplete, and thus the de facto ML includes abstract lexical structure from other sources, such as the L1. This is because 
L1 lexical structure or generalized TL lexical structure may "fill in" gaps in the de facto ML (Jake 1998: 362). The result is a composite ML constructed from TL-based IL lexical structure with elements from the L1.

As observed in any type of language-contact setting, the ML plays its dominant role in building the sentential frame by constraining the occurrence of EL system morphemes. This is also true in SLA, even if learners' ML is incomplete. Myers-Scotton (1997: 15) proposes the Morpheme Sorting Principle as follows:

Content and system morphemes from the linguistic systems contributing to bilingual CPs are subject to different constraints on occurrence. System morphemes come from the putative ML, but where there is insufficient access to this grammatical system, system morphemes are avoided or "not recognized" (i.e. they are reanalyzed as part of their lexical head) or both.

Jake specifies two conditions on the insertion of L1 lexical structure into the ML frame in SLA: “... only those gaps that the learner's grammar specifies as being projected by content morphemes" and “... only lexical structure projected by L1 content morphemes" can fill a gap in the ML (1998: 362). The first condition predicts that in building the composite ML underlying IL structures, L1 lexical structure can only fill gaps in content-morpheme lexical structure, and the second condition predicts that L1 lexical structure that fill gaps in the grammatical system underlying IL structures must be projected by L1 content morphemes. These two conditions restrict the role of the L1 in constructing IL structures. They are the consequences of the System Morpheme Principle (Myers-Scotton 1993: 83), subsumed in the Morpheme Sorting Principle cited above, which specifies that it is the ML that provides all system morphemes in constituents containing material from both the ML and the EL.

If we regard SLA as a particular language-contact phenomenon in which the intended target ML (i.e. the TL) is not completely available as a de facto ML, we assume that L1 abstract lexical structure can be 'split' and 'recombined' to build a developing target ML. However, the contribution of the L1 is constrained. Because the L1 is regarded as an EL, only abstract lexical structure projected by lemmas underlying L1 content morphemes can contribute to the developing composite ML. In other words, structures projected by lemmas underlying L1 system morphemes are blocked from contributing to the developing composite ML. However, under the assumption that system morphemes are accessed or activated differently, lemmas underlying content morphemes may indirectly elect some conceptually salient system morphemes (i.e., indirectly-elected system morphemes, rather than structurally-assigned system morphemes) in realizing the semantic and pragmatic features of directly-elected lemmas (i.e., content morphemes). Thus, it is possible for some abstract lexical structure of L1 indirectly-elected system morphemes to fill gaps in the developing composite ML.

The restricted role of the L1 in filling gaps in the abstract lexical structure underlying the developing IL system results in some unfilled ML gaps, especially ML system morpheme gaps, or some ML gaps to be filled by TL lexical structure along the IL continuum. The target-language principle recognizes that even though the TL is not the de facto ML, it is largely the TL lexical material out of which the developing IL is constructed. As more and more TL structures become available to learners, successful projections of TL structures will replace existing IL structures. Thus, unless the IL becomes fossilized, the de facto ML becomes more and more targetlike (see Jack (1998) 
for the complete introduction and discussion of the theoretical principles and constructs underlying this model of SLA).

\section{Conclusion}

This paper has examined the types of IL forms with multiple sources projected by learners from their developing IL grammars. It has demonstrated that IL structures can be predicted if certain assumptions are made about the nature of abstract lexical structure underlying IL system in relation to SLA. First is the assumption that the bilingual mental lexicon contains abstract entries called 'lemmas', and lemmas are language-specific and are in contact in second language learning. Second, abstract lexical structure is complex because it contains several discrete but interacting subsystems or substructures: lexical conceptual structure where components of given conceptual structure are lexicalized, predicate-argument structure where grammatical relations or patterns are realized, and morphological-realization patterns where surface morpheme order and inflectional morphology for grammatical functions are realized. Abstract lexical structure underlying IL system contains sources from more than one linguistic system. Third, parts of the lexical structure from L1 lexical entries (i.e., lemmas) may influence the lexical structure of incompletely acquired TL lexical entries in the developing IL. Thus, the linguistic system underlying IL contains complex lexical structure in which language-specific lemmas are in contact.

The IL performance data examined in this paper provide empirical evidence that SLA is a language-contact phenomenon. In language-contact situations, the languages in contact play unequal roles: the ML provides the grammatical frame of any constituent containing linguistic material from more than one language and both content and system morphemes, and the EL provides only content morphemes. In SLA, the ML is a composite with the TL as the intended ML and the abstract grammatical system underlying IL as the de facto ML (i.e., a composite ML), and the EL is the L1. Predictions based on the assumptions about the nature of abstract lexical structure underlying IL system in relation to SLA and the assumptions of the composite ML model of SLA have been illustrated by the IL performance examples for the study.

The composite ML model of SLA provides an explanation of the observation that in the development of more targetlike grammars, variations in linguistic forms precede functional accuracy. As Klein, Dietrich and Noyau note, "initially, there is coexistence of various morphological forms without appropriate functions," and "formal variation precedes functional use" (1993: 108). The contribution of the L1 as the EL to the de facto ML by filling gaps at various levels of abstract lexical structure is rather limited. It can only contribute projections of lexical structure of content morphemes (i.e., abstract entries in the mental lexicon as lemmas), and it only fills gaps in the lexical structure of ML content morphemes. Thus, the composite ML model predicts the inherent property of structural variation in IL, and the principles informing the model constrain the variation, so that it is systematic and largely predictable in nature.

To the extent that this model of SLA is valid, it offers several implications for understanding language acquisition and theories of language in general and SLA in particular. First, adult SLA is "fundamentally different" from first language acquisition 
(Jake 1998: 372). This is because adult second language learners are neither simply setting or resetting parameters based on positive input nor simply selecting abstract lexical categories out of a possible set of categories recognized as being 'universal'. Yet, what they are doing is similar to what bilinguals are doing in codeswitching. This similarity is based on the general principles governing the roles of each language involved in any contact situation. The mechanisms and processes in adult SLA are instances of those observed in other language-contact settings rather than those involved in L1 acquisition or the abstract categories of language themselves. Second, the notion of lexical structure recasts the observations that the principles-and-parameters research paradigm seeks to capture. As assumed, because parameter settings reflect morphosyntactic projections of abstract lexical structures, patterns of projected structures are recognized as parameters, and thus TL parameter resetting is in fact acquisition of subsystems of projected lexical structures. This means that in adult SLA, L1 parameters are not simply reset, but sufficient acquisition of TL lexical structure and substructures eventually results in the TL setting. In other words, the acquired TL lexical structure "takes over" the L1 lexical structure (Jake, 1998: 373). Third, the composite model of SLA also has implications for theories of language. One implication is that content morphemes are the basis for the linguistic system underlying every language, including IL. Since the ML underlying IL is recognized as the composite of two other natural languages, the TL and the L1, we can infer that these languages are also structured by projections of content morphemes (content morphemes are activated at the conceptual level). This means that it is the conceptually relevant linguistic structures that are central in projecting linguistic structure (e.g., lexical-conceptual structure and predicateargument structure). Thus, as assumed, linguistic structures underlying natural languages are driven by lexical elements (i.e., content morphemes) rather than by functional elements. This is because it is content morphemes that add lexical specifications, resulting in the 'required' projection of functional elements (i.e., system morphemes). This view does not entail a rejection of other models of language acquisition, such as a parameter-setting model of first language acquisition or a parameter-resetting model of second language acquisition.

\section{References}

Andersen, R. W. 1983a. Pidginization and Creolization as Language Acquisition. Rowley, MA: Newbury House.

Andersen, R. W. 1983b. Transfer to somewhere. In S. M. Gass and L. Selinker (eds) Language Transfer in Language Learning. Rowley, MA: Newbury House. 177-201.

Andersen, R. W. 1982. Determining the linguistic attributes of language attrition. In R. D. Lambert and B. F. Freed (eds) The Loss of Language Skills. Rowley, MA: Newbury House. 83-118.

Andersen, R. and Shirai, Y. 1996. The primary of aspect in first and second language acquisition: The pidgin-creole connection. In W. C. Ritchie and T. K. Bhatia (eds) Handbook of Second Language Acquisition. San Diego, CA: Academic Press. 527570. 
Bhatia, T. K. and Ritchie, W. C. 1996. Bilingual language mixing, universal grammar, and second language acquisition. In W. C. Ritchie and T. K. Bhatia (eds) Handbook of Second Language Acquisition. San Diego: Academic Press. 627-688.

Beniak, E., Mougen, R. and Valois, D. 1984/5. Sociolinguistic evidence of a possible case of syntactic convergence in Ontarian French. Journal of the Atlantic Provinces Linguistic Association 6/7, 73-88.

Bierwisch, M. and Schreuder, R. 1992. From concepts to lexical items. Cognition 41, 23-60.

Bock, K. and Levelt, W. J. M. 1994. Language production: Grammatical encoding. In M. A. Gernsbacher (ed) Handbook of Psycholinguistics. New York: Academic Press. 945-984.

Choi, S. and Bowerman, M. 1991. Learning to express motion events in English and Korean: The influence of language-specific lexicalization patterns. Cognition 41, 83121.

Chomsky, N. 1981. Principles and parameters in syntactic theory. In N. Hornstein and D. Lightfoot (eds) Explanations in Linguistics: The Logical Problem of Language Acquisition. London: Longman. 32-75.

Chomsky, N. 1986. Barriers. Cambridge, MA: MIT Press.

Cook, V. (ed). 2003. Effects of the Second Language on the First. Clevedon: Multilingual Matters.

De Bot, K. and Schreuder, R. 1993. Word production and the bilingual lexicon. In R. Schreuder and B. Weltens (eds) The Bilingual Lexicon. Amsterdam: John Benjamins. 191-214.

Dechert, H. and Raupach, M. (eds). 1989. Transfer in Language Production. Norwood, NJ: Ablex.

Dewaele, J. M. 1998. Lexical inventions: French interlanguage as L2 versus L3. Applied Linguistics 19, 471-490.

Dorian, N. 1981. Language Death: The Life Cycle of a Scottish Gaelic Dialect. Philadelphia: University of Pennsylvania Press.

Dulay, H. C., Burt, M. K. and Krashen, S. D. 1982. Language Two. New York: Oxford University Press.

Eckman, F. 1977. Markedness and the contrastive analysis hypothesis. Language Learning 27, 315-30.

Færch, C. and Kasper, G. (eds). 1987. Introspection in Second Language Research. Clevedon, Avon: Multilingual Matters.

Gass, S. M. 1984. A review of interlanguage syntax: Language transfer and language universals. Language Learning 34, 115-32.

Gass, S. M. 1996. Transference and interference. In H. Goebl, P. H. Nelde, Z. Starý and W. Wölck (eds) Kontaktlinguistik: Ein Internationales Handbuch Zeitgenössischer Forschung. Vol. 1. Berlin: Walter de Gryuter. 558-567.

Gass, S. M. and Selinker, L. (eds). 1983. Language Transfer in Language Learning. Rowley, MA: Newbury House.

Gass, S. M. and Selinker, L. (eds). 1992. Language Transfer in Language Learning. Amsterdam: John Benjamins.

Giacobbe, J. 1992. A cognitive view of the role of L1 in the L2 acquisition process. Second Language Research 8.3, 232-50. 
Givón, T. 1984. Universals of discourse structure and second language acquisition. In W. E. Rutherford (ed) Language Universals and Second Language Acquisition. Amsterdam: John Benjamins. 109-136.

Hatch, E. 1983. Psycholinguistics: A Second Language Perspective. Rowley, MA: Newbury House.

Jackendoff, R. 1990. Semantic Structures. Cambridge, MA: MIT Press.

Jackendoff, R. 1991. Parts and boundaries. Cognition 41, 9-45.

Jake, J. L. 1994. Intrasentential codeswitching and pronouns: On the categorical status of functional elements. Linguistics 32, 271-98.

Jake, J. L. 1998. Constructing interlanguage: Building a composite matrix language. Linguistics 36, 333-82.

Kamwangamalu, N. and Li, C. L. 1991. "Mixers" and "mixing": English across cultures. World Englishes 10, 247-61.

Kellerman, E. 1986. An eye for an eye: Crosslinguistic constraints on the development of the L2 lexicon. In E. Kellerman and M. Sharwood Smith (eds) Cross-linguistic Influence in Second Language Acquisition. Oxford: Pergamon. 35-48.

Kellerman, E. and Sharwood-Smith, M. (eds). 1986. Cross-linguistic Influence in Second Language Acquisition. Elmsford, NY: Pergamon Press.

Klavans, J. L. 1985. The syntax of code-switching: Spanish and English. In L. D. King and C. A. Maley (eds) Selected Papers from the 13th Linguistic Colloquium on Romance Languages. Amsterdam: John Benjamins. 213-231.

Klein, W., Dietrich, R. and Noyau, C. 1993. The acquisition of temporality. In C. Perdue (ed) Adult Language Acquisition: Cross-linguistic Perspectives, Vol. 2. Cambridge: Cambridge University Press. 73-118.

Kuhberg, H. 1992. Longitudinal L2-attrition versus L2-acquisition, in three Turkish children - empirical findings. Second Language Research 8.2, 138-54.

Lado, R. 1957. Linguistics across Cultures: Applied Linguistics for Language Teachers. Ann Arbor, MI: University of Michigan Press.

Levelt, W. J. M. 1989. Speaking: From Intention to Articulation. Cambridge, MA: MIT Press.

Levin, B. and Pinker, S. 1991. Introduction. Special issue of Cognition on Lexical and Conceptual Semantics. Cognition 41, 1-7.

Major, R. 1987. Phonological similarity, markedness, and rate of L2 acquisition. Studies in Second Language Acquisition 9, 63-82.

Myers-Scotton, C. 1993 [1997]. Duelling Languages: Grammatical Structure in Codeswitching (1997 edition with a new Afterword). Oxford: Clarendon Press.

Myers-Scotton, C. 1994. Language processing and the mental lexicon in bilinguals. In R. Dirven and J. Vanparys (eds) New Approaches to the Lexicon. Frankfurt: Peter Lang. 73-100.

Myers-Scotton, C. 2002. Contact Linguistics: Bilingual Encounters and grammatical Outcomes. New York: Oxford University Press.

Myers-Scotton, C. and Jake, J. L. 1995. Matching lemmas in a bilingual language competence and production model: Evidence from intrasentential code switching. Linguistics 33.5, 991-1024.

Myers-Scotton, C. and Jake, J. L. 1999. Giving structure to creoles. Paper presented at the Annual Conference on Pidgin and Creole Language, Los Angeles. 
Myers-Scotton, C. and Jake, J. L. 2000. Four types of morpheme: Evidence from aphasia, codeswitching, and second language acquisition. Linguistics 38.6, 1053-100.

Nishimura, M. 1997. Japanese/English Code-switching: Syntax and Pragmatics. New York: Peter Lang.

Odlin, T. 1989. Language Transfer. Cambridge: Cambridge University Press.

Pfaff, C. 1979. Constraints on language mixing: Intrasentential code-switching and borrowing in Spanish/English. Language 55, 291-318.

Pinker, S. 1989a. Learnability and Cognition. Cambridge, MA: MIT Press.

Pinker, S. 1989b. Resolving a learnability paradox in the acquisition of the verb lexicon. In M. L. Rice and R. L. Schiefelbusch (eds) The Teachability of Language. Baltimore, MD: Brushwood Graphics. 13-61.

Polinsky, M. 1997. American Russian: Language loss meets language acquisition. In W. Browne, E. Dornish, N. Khondrashova, and D. Zec (eds) Annual Workshop on Formal Approaches to Slavic Linguistics. 370-406.

Radford, A. 1990. Syntactic Theory and the Acquisition of English Syntax. Cambridge, MA: Basil Blackwell.

Rappaport, M. and Levin, B. (1988) What to do with theta-roles. In W. Wilkins (ed) Syntax and Semantics, Vol. 21: Thematic Relations. New York: Academic Press. 734.

Ringbom, H. 1987. The Role of the First Language in Foreign Language Learning. Clevedon, Avon: Multilingual Matters.

Romaine, S. 1989. Bilingualism. Oxford: Blackwell.

Seliger, H. W. 1996. Primary language attrition in the context of bilingualism. In W. Ritchie and T. Bathia (eds) Handbook of Second Language Acquisition. New York: Academic Press. 605-627.

Shirai, Y. 1989. The acquisition of the basic verb PUT: Prototype and transfer. Unpublished master's thesis, University of California, Los Angeles.

Talmy, L. 1985. Lexicalization patterns: Semantic structure in lexical forms. In T. Shopen (ed) Language Typology and Syntactic Description, Vol. 3. Cambridge: Cambridge University Press. 57-149.

Tanaka, S. 1983. Language transfer as a constraint on lexico-semantic development in adults learning a second language in acquisition-poor environments. Unpublished doctoral dissertation, Columbia University, Teachers College, New York.

Traffers-Daller, J. 1991. French-Dutch language mixture in Brussels. Unpublished doctoral dissertation, University of Amsterdam.

VanPatten, B. 1984a. Processing strategies and morpheme acquisition. In F. Eckman, L. Bell and D. Nelson (eds) Universals in Second Language Acquisition. Rowley, MA: Newbury House. 88-98.

VanPatten, B. 1984b. Learners' comprehension of clitic pronouns: More evidence for a word order strategy. Hispanic Linguistics 1, 57-67.

Wei, L. 1994. Organizing principles governing early second language acquisition. Paper presented at the Annual Meeting of New Ways of Analyzing Variation (NWAV), Stanford University, CA.

Wei, L. 1995. Chinese and Japanese learners' interlanguage data. Unpublished.

Wei, L. 1996a. Organizing principles behind codeswitching and interlanguage development in early adult second language acquisition. In J. Arnold, R. Blake, B. 
Davidson, S. Schwenter, and J. Solomon (eds) Sociolinguistic Variation: Data, Theory, and Analysis. Stanford, CA: CSLI Publications. 417-431.

Wei, L. 1996b. Variation in the acquisition of morpheme types in the interlanguage of Chinese and Japanese learners of English as a second language. Unpublished doctoral dissertation, University of South Carolina, Columbia, SC.

Wei, L. 2000a. Unequal election of morphemes in adult second language acquisition. Applied Linguistics 2, 106-140.

Wei, L. 2000b. Types of morphemes and their implications for second language morpheme acquisition. International Journal of Bilingualism 4.1, 29-43.

Wei, L. 2001. The Multilingual mental lexicon: Language separation/activation in trilinguals. Papers Selected from the Second International Conference on Third Language Acquisition and Trilingualism: Interactive CD-ROM. Fryske Akademy (2002).

Wei, L. 2002. The bilingual mental lexicon and speech production process. Brain and Language 81, 691-707.

Wei, L. 2003. Activation of lemmas in the multilingual mental lexicon and transfer in third language learning. In J. Cenoz, B. Hufeisen and U. Jessner (eds) The Multilingual Lexicon. Dordrecht: Kluwer Academic Publishers. 57-70.

Zobl, H. 1980a. The formal and developmental selectivity of L1 influence on L2 acquisition. Language Learning 30, 43-57.

Zobl, H. 1980b. Developmental and transfer errors: Their common bases and (possibly) differential effects on subsequent learning. TESOL Quarterly 14, 469-79. 